\title{
Appraising the Coverage of Gender in Geography Education in Uganda Secondary Schools
}

\author{
Prof. Alice Merab Kagoda \\ Makerere University, School of Education \\ Kampala, Uganda
}

\begin{abstract}
Geography is an interdisciplinary subject which includes both the physical and human components. It is about the relationship between the people and the physical environment, as well as the interaction among people themselves. The environment in which people live changes in time and space making geography a dynamic subject which call for constant change in the content and the methodology of teaching it. Gender is one of the current issues in society which help to explain the low levels of development in most developing countries. This paper critically examined the 0 -level geography to identify topics where it can be integrated, as well as, recommending methods can be used to teach it. The author recommends that the government of Uganda should integrate gender in the geography teaching syllabus, train teacher through in-service programmes to sensitize them about the importance and values or integrating gender in the subject. The Uganda National Examinations Board should be oriented to current issues in education and set questions relevant and appropriate to gender issues.
\end{abstract}

Key words: Geography Curriculum, gender, pedagogy

\section{INTRODUCTION}

Geography is a discipline of study in the secondary school curriculum in Uganda. It is a compulsory subject at the ordinary level and optional at advanced level of education. The content of Geography includes understanding spatial patterns and processes on earth. The earth is composed of living and non-living elements. Geography is also concerned with the spatial dimension of human experience (space and place) in a historical perspective; that is when events occurred and how events are related to each other. The economic perspective focuses on how people produce, exchange goods and services to fulfil each need such as food, shelter, transportation and recreation. Earning a living, developing and trading resources, producing and distributing products and services is central to economic Geography. Understanding the integration of local, regional, and national economics with the global economy is critical to knowing how people interact (Geography for life 1994). Geography is a dynamic subject that changes over time and space therefore its content and pedagogical approaches must also change accordingly. Hence the changing character of gender in a changing environment is one of the new trends which geography education has to address

The Geography syllabus for secondary schools in Uganda was designed within the modernization paradigm which doesn't focus on people and their welfare. The syllabus focuses on economic development with emphasis on exploitation of resources at the expense of care and preservation of the environment (Kagoda 1997). This approach doesn't consider how modernization might impact negatively on the spiritual, social, and political development. There is little concern for equitable distribution of resources and benefits among all people. Every society has gender-based division of labour; however, there has been a blind adoption of development programmes that promote a western model of economic growth as a means of 
improving standards of living (Prorok \& Chhokar 1998). This kind of Geography education is not real and is de-contextualized to the Ugandan students. Cartier (1998) argues that Geography of gender is critical to understanding complex issues of population growth, agriculture, climate change, environmental issues, industrialization, and basic human rights. This paper explores how gender can be integrated in the Geography curriculum for secondary schools in Uganda in order to meet the needs of the students and the society at large.

\section{The concept of gender}

Hyde (1993) defines gender as:

"the social meaning given to being either a man or a woman in a given society and to expectations held as to characteristics, attitudes, and likely behaviour of man and woman. It involves both ideology and material practices and such behaviour/activity which is the hallmark of felinity i.e. impregnated with gender. (pp 24).

It is thus assumed that physical difference (body characteristics) influence mental traits, which in turn influence attitudes and predispositions, those differences are both natural and unproblematic. However gender differences and the experience of differences are socially and psychologically created and situated. Acquisition of social characteristics of insecurity or femininity is a highly complex set of processes involving both psychological events and socialization which starts almost at breastfeeding level and continues well into adulthood. It involves acquiring an identity (social/and sexual) and learning a set of differentiated behaviours and capacities appropriate to the masculine or the feminine. Through continued socialization at schools, home, through games and rituals and even the sexual discipline of labour, girls and women learn these behaviours and capacities appropriate to their gender and their culture.

Gender roles do exist in all societies although they are changing today in some communities. This changing character of gender in a changing environment is one of the new trends which Geography education has to address. Values of integrating gender in geography education include among others; students internalising the fact that women constitute half of the world population, one third of the official labour force, perform nearlr two thirds of work hours but receive one tenth of world's income and less than one hundredth of world property. Research and studies should concentrate on processes that produce women's subordinate position; social and spatial relationships that take place within homes and buildings would make students of geography aware of the violation of women's rights and hopefully change the situation in Society.

\section{The modernization Paradigm and Geography syllabus in Uganda}

The term modernization means the pursuit of a particular development paradigm or pattern by industrialized countries in cooperation with their allied elite Southern countries. This involves amassing material wealth through capital investment with a high motive toward profit maximization. Industrialized nations benefit from this development through unequal trade, investments globally and aid. There is a strong belief in the trickle down theory that emphasizes growth over equity and maximal exploitation of the environment. Advanced technology is deemed essential to growth, including the modernization and commercialization of agriculture with an emphasis on export oriented cash crops at the expense of food crops. Large-scale infrastructure and private enterprise is favoured; women's productive roles are de-emphasized and under rewarded. Famine and hunger are believed to be a result of drought and natural hazards. Over population is believed to be the major cause of underdevelopment and can be controlled by governments. Modern formal education is deemed as helping development and growth by generating human capital. There is a belief that advanced 
industrialized consumer life style can be universalized and the southern societies can catch up (Toh 1987; George 1976). A modernization paradigm emphasizes economic development based on certain biases and assumptions of human programs in economic, political, social, cultural, and intellectual spheres. This paradigm is used in this study to explain the structure and content of the Geography syllabus in secondary schools in Uganda.

\section{Contextual framework}

The writer used the Geography teaching syllabus for senior 1- 4 revised by the Ministry of Education and Sports (MoES) in 2008 to critically analyze the coverage of gender in its scope and content as well as teaching methods. It is important to note that this syllabus replaced the one developed in 1972 which in turn replaced the colonial Geography teaching syllabus. Revision of the syllabus is sponsored by Western countries because the government does not have sufficient funds of writing, piloting, and finally implementing a new syllabus. The sponsors have a strong influence on what content is included in the syllabus, including the teaching materials which are written and published outside Uganda. The aims of teaching Geography for the 1972 and 2008 syllabi are similar but with slight improvements especially recognizing gender in objectives except that of number three and four where "his" is used.

\section{Aims of Teaching Geography include among others}

To enable the student:

To be aware of, interested in, and care for her/his immediate environment; acquire the appropriate attitudes and skills with which to interpret and develop that environment including those of recording and analyzing; acquire knowledge and understanding of the relevant aspects of the larger environment in which the community exists by selecting topics of particular applicability to his environment; acquire the ability to use Geographical knowledge of the larger environment in which the community and country exist by selecting topics of particular applicability to his environment; interpret photographs depicting both physical and human features, and representing or interpreting geographical statistics and understand fieldwork techniques and study local areas in the field. First and foremost objectives (iii) and (iv) were formulated for the male student

\section{Scope and Depth}

The secondary school Geography content in the syllabus includes studies in North America, East Africa, Fieldwork, Map work, Photograph Interpretation, Rhinelands and the Rest of Africa. The topics to be covered under China are outlined at the end of the syllabus.

Another important aspect of education in Uganda is that the education system is examination oriented. Therefore teachers teach what they speculate will be examined in the national examinations. The people who set these examinations do not seem to be aware of the current trends locally or globally, such as gender in development issues. The teaching materials in response to the current curriculum are the same as those of 1972 and these are clearly outdated.

Today in most developing countries like Uganda, Geography is still focused on concepts and big ideas of spatial distribution and spatial interaction, relative location, centrality and accessibility networks and nodal regions. This Geography is de-contextualized and separated from its real world, and is expressed in a language which misleads children about how society operates. Distant places are taught to the children without relating it to their familiar home experiences which are largely ignored. Economic development is emphasized at the expense of 
the welfare of people, and values of the affluent western society are imposed on the students in the third world. There is a belief that poor regions can develop through big dams, green revolution, irrigation schemes and urban industrialization (Slater 1977).The themes emphasized in the Geography syllabus in secondary schools of Uganda include: the physical environment of all regions studied, development of agriculture using high technology, mining, industrial development, extensive farming, multipurpose development schemes and river development to mention a few topics (MoES 2008). The effect of these development schemes on the lives of people is never critically analyzed in Geography classrooms.

The Geography curriculum leaves out topics on woman's contributions to development, structural violence, human rights and appropriate technology, culture, injustice and political economy. All countries depend upon their citizens' knowledge of the local and world economy, the cultures of the diverse people who share our planet, but this is not adequately presented in secondary schools in Uganda. These components of human and economic Geography are presented in Geography classrooms as if human beings do not exist in the places being described.

\section{STATEMENT OF THE PROBLEM}

Geography as a school subject focuses on three main components; the physical environment, the social environment, and the created environment. Each component has many subcomponents which interact with each other within and across the component boundaries. These components vary in their characteristics over space; one or two may dominate, thereby defining a place, while in a majority of many places various components interact (Johnston 1993). The understanding of these various components, their interaction and the impact of such interaction is the core of geographic scholarships. The way Geography is defined over time affects the way it is taught in schools and universities. Today Geography students in Uganda, in all secondary schools and tertiary institutions define the subject as the study of man and his environment leaving out the women in this definition, according to my observation as a geography teacher trainer. While men are implied as the main focus in the study of Geography, both genders are not appropriately integrated in the content presented in Geography classrooms. Because of the changing nature of society locally and at global level, Geography education should help students discover current realities of life through gender integration in the syllabus. The question is how can teachers be guided to adopt gender sensitive content and pedagogy in the implementation of this syllabus?

\section{Purpose}

The main purpose of the study was to explain and identify areas where both genders can be integrated in the content +and pedagogy of Geography education.

\section{Objectives}

1. To critically analyze the content of the Ordinary-level Geography curriculum in secondary schools in Uganda.

2. To identify areas/Topics the secondary school Geography syllabus in which gender can be integrated.

3. To make recommendations on the pedagogical approach to integration of gender in the secondary school Geography syllabus.

\section{METHODOLOGY}

The study was mainly an analysis of documents and literature review. The writer critically analyzed using Oberhausen's suggestion that: 
"Geographers have began to recognize the importance of gender in understanding spatial patterns and social dimensions of human activity. Answers to questions such as, who does what? Who gets what? Where? And Why? Increasingly, address how space relates to gender and how people are socialized into certain masculine and feminine roles" (pp 1).

Anderson (2011) argues that a community based learning helps students understand individual roles and responsibilities in communities and relationships between those individuals. This implies teachers guiding students investigate those community relationships using teaching methods that develop critical thinking and skills working with local people. A few topics in the Geography curriculum are discussed below under the objectives formulated above.

\section{Presentation of Data}

Objective one: The Ordinary-level syllabus content

Geography has the advantage of being interdisciplinary with a global vision both spatially and thematically. This section focuses on the content covered in the Ordinary-Level Geography syllabus in Uganda.

Agriculture in Geography focuses on three main themes namely: cultivation, animal husbandry, and fishing.

In developing countries, "a dual economy" is the dominant characteristic of their production: the modern urban economy composed of the elite and the traditional poor rural economy which is at subsistence level. Teaching about agriculture normally focuses on cash crops like coffee, cotton, tea, sisal, cocoa, groundnuts, rice, tobacco, pyrethrum, flowers etc. Traditional agriculture focusing on food crops is ignored and this probably leads to good insecurity in the country.

Land in most developing countries belongs to men. In Uganda for example, only $7 \%$ of the registered land belongs to women. In patrilineal societies women are subordinate to men and play a very limited role in household or communal decisions. In matrilineal societies the situation is not different since the lands the women cultivate belong to their brothers and uncles. In Tanzania Ishengoma (2004) writes that legally women and men have equal access to land, however, such access is often reserved for males. Patriarchal relations of production exploit women and perpetuate the control of land and women's labor and time by men. Men inherit the land and control the critical inputs for agricultural products as well as proceeds from the sale of crops produced by women and children. Food production which is a woman's job is not regarded as important in Geography classrooms. The effect of producing cash crops on prime land is not recognized as a problem and a contributing factor to famine and hinder in some region under study. This unequal access to land and family property (cash) is not a topic in geography classrooms. The students (male and female) do not recognize this structural violence and do not discuss it in class.

Today some of these food crops are now cash crops to urban population and sometimes exported to neighboring countries. For example maize, sweet potatoes, Irish potatoes, beans, banana, cassava, and a variety of fruits are grown by women in Uganda. These crops are grown on small scale, $1 / 2$ acre but due to necessities at home namely medical expenses, clothing etc for the family the women sell some of these crops. The majority of women, do not own the land they utilize, explaining why the men take over as soon as the crops are ready for sale (Kagoda 
2008). Women in some African societies are subordinated to men because of the culture of paying dowry, making them a property to their husbands. They cannot make a decision on the utilization of land and how to conserve it which has led to large scale degradation of land. In the highlands of south-eastern Uganda, and the highlands of Ethiopia where land is cultivated by illiterate women striving for survival, modern land conservation practices like terracing, intercropping mulching, planting trees, agro-forestry are not practiced at all because women feel they cannot conserve what doesn't belong to them (Kagoda 2008). In Uganda and China, women provide $60 \%$ of agricultural labor, which activity is labor intensive, back-breaking, and time consuming especially during planting, weeding, and harvesting and processing (Prorok \& Chhoko 1998). Men at times help in clearing fresh fields and as mentioned before, some women lack access to casual laborers because of the limited funds they have. This kind of information is never mentioned in Geography classrooms, reason being that it doesn't appear in the national examinations.

Secondly the Geography textbooks and pamphlets do not contain such information. Thirdly teachers do not task students in their classes to narrate their lived experiences at home. What is valued in Geography classrooms is the written textbook information and nothing else. This explains why Geography teachers fail to tell their learners that one contributing factor to poor productivity of peasant farmers is that it is the illiterate women who are responsible for both food and cash crop production on land they do not own.

As regards the modern farms where tea, sugarcane, sisal, and coffee plantations have been established, the people working there are regarded as factors of production. As a factor of production, the number of people employed is mentioned but this data doesn't tell the gender of those people. It is never mentioned that most of the men working in such plantations and associated factories are given a salary below their living expenses. Their lived experience in their residential areas and at work is never discussed in the classrooms. The fact that women in rural areas subsidize these plantations and factories by sending food to their husbands/sons is never mentioned in the Geography classrooms.

The woman and men who pick tea or cut sugarcane in the plantations are not mentioned in the Geography classes. The large scale plantations are owned by foreign investors who have the cash to cultivate on large scale. As long as governments get the taxes, which is invested in the modern sectors, the poorest of the poor especially women are ignored. This information doesn't appear in Geography lessons on the topics; plant and animal husbandry, especially traditional pastoralist like the Masai, Karamojong, Fulani, the Hima, and Tutsi, etc. These are people living in a precarious environment with little rain, therefore shortage of water for domestic work and animals, very hot temperatures. Survival in these environments is difficult, hazardous and one needs to understand the history of these people, their survival tactics and their daily experiences. The age of men who move with these animals, the work of women, the new trends in these communities is not known and their experiences is not mentioned. This topic is taught as if there are no individual people with daily experiences, which need to be addressed. For example women in such societies are responsible for building residential houses a fact not known by the majority of people in East Africa. The experience of women as reproducers of humanity in such remote precarious environments is not discussed in Geography classrooms. The modern animal husbandry farms, fenced with barbed wire or live fences, with hybrid animals are taught in Geography classes to students, however, it is never pointed out who are the owners, who are the workers, the age and sex of these workers as well as their responsibilities. The small scale animal rearing involving looking after animals like rabbits, goats, sheep and looking after local chicken is normally an activity for women in many 
rural households. Such activities, however, never appear at all in the Geography textbooks nor are they mentioned by teachers in the class.

Fishing is an important topic in the secondary school Geography syllabus. Large scale fishing normally carried out on large seas in Indian Ocean, Atlantic, Mediterranean Seas by foreign ships from Japan, Russia etc is mentioned. However, the way the information is presented gives the impression that there are no people on these ships; no men or women on these factory ships mentioned. The small scale local fishing on the rivers, lakes, and swamps in Africa is taught but there is no mention of women participants in this economic activity. It is implied that this is a task dominated by men but it is not mentioned that large numbers of underage, boys who abandon school to go fishing. The daily experience of the fisher folk of poor sanitation, poor housing, hazards on the rivers and lakes, to mention a few challenges, is not a concern of the Geography teachers.

The large scale multipurpose development schemes like Tennessee Valley Authority, Volta River development scheme, the Aswan high dam, Kilombero River Sugar scheme, The Tana River Rice scheme, the Rhine river, the Aswan High Dam, the St. Lawrence Seas Way etc. are some of the contents in the Geography taught in secondary schools. These are development schemes which are abstract since the majority of students have never seen them; the photographs, if available, show men in action not women. Although the purpose of teaching them is to enable students aspire for and copy this modern technology, the message intended to be passed on to the students is not captured. Some rural students imagine the Dutch people who claimed the sea are magicians because there no are teaching material to illustrate how is done. The benefits that could trickle to the poor through the elites in the developing countries like the Netherlands are not mentioned. The women who are landless and with no security to secure loans cannot dream of buying expensive machines. Above all there are no role models for women in developing countries to emulate since female economic activities are not reflected in the content of North America and The Rhine Lands. Lastly peasant farmers, the majority of whom are women, cannot afford the costs of hybrid seeds and animals, chemicals for fertilizing the land and insecticides to modernize agriculture. Local initiative in handcrafts by both men and women are being made in many countries studied in the syllabus but this is not taught. Geography students are made to believe that development of their country will come from outside with the foreigners they study about in North America, the Rhine lands and the development schemes in Africa..

It is not mentioned where the people moved to when their land was flooded as these dams were being constructed. The people in the St Lawrence Sea Way are not talked about; the people who polluted the Rhine River are not appropriately discussed. The experiences of the people in such areas are essential for enabling secondary school students to understand the relationships between them and the environment they live in.

The topic urban Geography whether in developed cities like New York, or Kampala, Accra, Nairobi, Lagos or Addis Ababa, the experiences of people who live in such cities is never taught. The people who live in the powerful perimeter walled houses are not mentioned. This gives the impression that New York, a topic in O-level Geography is a place of skyscrapers with no people living them. The high class people living in such cities are detached from their culture and live a miserable lonely life where one has to make an appointment to be accepted as a visitor. These lonely people and the general happiness of the rural people in Africa and the urban slums in general are not talked about. The congested slums, the number and gender of 
the people in these slums are not taught. The underlying causes of poverty and street children are not appropriately explained to the students. The concept structural violence is not known by teachers and hence cannot be used to explain the urban and rural poverty in developing countries.

In the area of commerce, trade and industry the teachers mention the goods and services involved. The unfair and unequal trade between the developing and western countries is explained without mentioning the traders involved, whether men or women. Today many women have joined the local and international trade, but this is not discussed in the Geography classroom. The weekly markets in all areas of Uganda whether urban or rural are an important source of geographical knowledge. The women and men buying and selling goods in such weekly markets are not integrated in Geography. The daily farmer's markets in urban areas should be analyzed to identify the gender of the people involved. Political Geography is completely neglected yet the people involved whether men or women should be discussed to explain their motivation to participate in the politics of the area but this is ignored. For example the new political system and practices in Uganda with affirmative policies embedded in it should be part and parcel of the Geography syllabus.

\section{Culture}

Religion and social values are visible expressions in the landscape and in spatial phenomena and patterning (Pinchemol 1982). These are reflected in land use, food, taboos, settlement patterns, house types, division of labor, music and dance, and agricultural practices. Smith (1978) argues that exploration of people's feelings and emotions through music, art, drama, and personal experience is an important part of learning in the area of knowledge. Geography is concerned with religion because it has a relationship with the world. Ideas, beliefs, rituals and politics are part of the production processes. Religion creates social cohesion, reflects social morality, and reaffirms society. Religion prescribes conduct, legitimates socio-political order and channels human motivation and interests, as well as being a habitualized, routinized form of human interaction. This interaction on a religious basis is not regarded as important geographic information to be taught to students. The Geography content discussed above is not exhaustive; only a few topics are discussed to illustrate the short comings of the syllabus in the aspect of gender.

\section{Instructional Materials}

Few schools have updated text books. These were written and published in Western countries eg. Text books on topics like The Rhine lands, North America, China and Africa were published before the current curriculum was written in 1970's. Some geography teachers have taken the initiative to write what geography is referred to as "pamphlets" for students to use to answer external examinations. These pamphlets are not comprehensive and their source of content is questionable since some of it is wrong. (Kagoda 2016) source of information for teachers with no access to internet. Newspapers and journals are impossible. Atlas maps are not available for over $90 \%$ of the students is over $85 \%$ of the schools and colleges (Kagoda 2016) this is similarly observed by Adenogba (2011) in Nigeria. Consequently geography in secondary schools is taught at high level of obstruction in spite of the numerous concepts, ideas, place names and new trends in the subject.

\section{Pedagogy of Gender and Geography Education}

Mlana et al. (2005) argues that many teachers apply teaching methods that do not give boys and girls equal opportunities to participate. They also use teaching materials that perpetuate gender stereotypes. Pedagogy is a concept that enhances all teaching and learning processes. This includes what is taught, how teaching takes place and what is taught is leant. Gender 
perspective pedagogy refers to teaching and learning processes that pay attention to the specific learning needs of girls and boys. This calls upon teachers to take on all encompassing gender approach in the process of lesson planning, teaching, and class management and performance evaluation. Some teachers are not aware that socialization and cultural conditioning may leave girls fearful or reluctant to touch teaching materials. Girls are brought up not to speak outline public are not likely to participate in lessons/activities that require them to separate like in debate.

This kind of Geography will utilize dialogical and discovery methods with emphasis on learner activity and an open-ended approach which aims to provoke thought and stimulate creativity. These methods educate students for democratic, participatory, cooperative processes within the classroom (Smith 1978). Learner-centered pedagogies are advocated for in new theories of learning and teaching, confirmed by Hamm (1996). Cooperative learning, constructivism, competence-based, etc are transformative in that learning is more democratic and participatory. It will also promote reflective thinking to social problems or situations that confront a specific learner or group of learners. They will also examine their individual values as well as values of others. This method builds upon the needs, interests and realities of students. This inquiry method works on the basis that one enjoys and learns best that he/she believes in and that which makes sense to him/her will develop a feeling of humanness for society because she/he is viewing society through his/her own perspective (Freire 1972). However, these teaching methods are not utilized frequently by reply teachers on the premises that they are time consuming when planning a lesson and yet they are effective in the learning.

Another method that can be utilized to involve students in their learning is use of "private Geography". Traditionally, the learner is seen as a naïve subject whose history of experience and milieu are neglected but in fact, the learner normally has personal knowledge and a conceptual framework developed through experience which could be taken into account. Fein (1980) defines private Geography thus:

"Private Geography comprises of the many personalized environmental images values and skills that a person stores in his memory to assist him in making decisions about the location and attributes of phenomena experienced in the everyday spatial environment. It thus has a designative and an appraisal function. Private Geography contains a cognitive representation of all the places and landscapes one has inhabited, visited, imagined or seen through the media. The appraisal aspects of the images have a far wider application. They control environmental beliefs, discussion making and behavior and thus influence what we do, where in and to the environment" (Fein 1980 P 410).

Private Geography is therefore a general frame of reference within which the individual can act or to which he/she can attach his/her knowledge. It contains personal cultural views, personal traits and even imaginative and incomplete recollection of places and landscapes (Graves 1982). Gender responsive pedagogy in a typical geography lesson.

\section{Sample Lesson - Class Senior.4; ( 16-17 years)}

Topic: Rice Growing in Eastern Uganda.

\section{Aim}

To enable students to understand and appreciate the role of women in agriculture in Uganda. 


\section{Objectives}

1. The students will identify the land tenure system in the societies of Eastern Uganda.

2. Students will identify activities involved in rice growing.

3. Students will evaluate roles played by each gender in the production of rice in each household.

\section{Methods}

Role play, brain storming, library research, small group discussions, and music.

\section{Teaching Materials}

Atlas, National Environment Management Authority Reports, newspaper reports, textbooks if any.

\section{Expected outcome}

Students will enhance their research skills, develop teamwork and reading creative skills.

The students will have a deeper understanding of patriarchy and its exploitation of women and children.

\section{Project work - 2 weeks}

Students will work in groups of 4

\section{Content}

- Location of Rice growing areas in Eastern Uganda.

- Streams and Swamps draining into Lake Kyoga in Namutumba, Pallisa, Butaleja Districts.

- The landforms of the area of study

- The climate of the region

- The population; its structure and distribution

- The social and economic activities of the people

- Agriculture and the land tenure system

- Rice growing and its related activities like: clearing fields, planting, weeding, scaring away birds, harvesting, drying, marketing

- Responsibilities of men and men in Rice growing including decision making

\section{Procedure}

The students will be introduced to the topic by brainstorming about peasant farming in Uganda.

Students in groups will discuss the activities involved in rice cultivation through library research. Students will be encouraged to use peers who come from south eastern Uganda.

The teacher can invite a Guest Speaker from that area to talk about the topic.

\section{Note}

The groups will report to the class after three weeks in form of poems, music, debate, pictures, drama etc.

\section{CONCLUSION}

One has to be gender sensitive in order to identify topics in the Geography curriculum where both genders are not represented in the curriculum. 


\section{RECOMMENDATIONS}

The Government of Uganda through the National Curriculum development Centre should integrate gender in the geography syllabus and summative examinations, since teachers teach what appears in examinations

The Ministry of Education and Sports should organize in-service seminars/workshops to sensitize them about the importance and values of integrating gender in the subject.

Gender responsive content and pedagogy should be introduced in teacher training colleges and in-service seminars

The geography panel in the National Curriculum Development Centre should be gender sensitized by the Ministry of Education and Sports.

\section{References}

Annan-Yao, E. (2004). Analysis of gender relations in the family, formal education, and health. In Bashaw, Z. (Ed.). Gender, economics, and entitlement in Africa, (pp. 1-17). Dakar, Senegal: Council for the Development of Social Science Research in Africa.

Bashaw, Z.N (2004). Trajectories of Women; Environmental Degradation and Scarcity; Examining Access to and Control over resources in Ethiopia. Radical Geography. Chicago Maarauta Press.

Boserup. E. (1990). Population, The Status of Women and Rural Development. In G

McNicoll \& M. Cain (Eds.). Rural Development and Population Institutions and Policy(pp, 45-59). New York; Oxford University Press.

Brock-Utine.B. (1989). Feminist Perspective on Peace and Peace Education. London. Pergamon Press.

Cartier. C.L (1988) Women and Gender in Contemporary China. Indiana. National Council for Geographic Education.

Fein. J.(1980) Operationalizing the Humanistic Perspective in Geography Education. Geographical Education 3,pp507-553

Frere, P. (1972). Pedagogy of the Oppressed. New York. Herder and Herder

Geography for Life (1994). National Geography Standards 1994 In National Council for Geographic Education George, S, (1976). How The Other Half Dies. Ringwood. Penguin

Graves. N.J. (1982) The evaluation of Geography. In Graves. N.J.(Ed) New UNESCO Source Book For Geography Teaching (pp 314-363) Paris: The UNESCO Press.

Hamm. M. \& Adams, D. (1996), Cooperative Learning: Critical Thinking and Collaboration Across the Curriculum. Springfield: Charles C. Thomas. Publisher.

Hyde. K.(1993) Sub-Saharan Africa: in King and Hill A.M (eds.) Women's education in Developing Countries, Barriers, Benefits and policies. Washington.

Ishengoma (2004) Accessibility of Resources by Gender: the case of Morogoro region in Tanzania. In Bashaw, Z. (Ed.). Gender, economics, and entitlement in Africa, (pp. 53-66). Dakar, Senegal: Council for the Development of Social Science Research in Africa.

Oberhauser. A. (2010) The Geography of Gender: A Global View. www.geo.wvu.edu/-oberhauser

Johnston, R.J (1993). Meet the Challenge, Make the Change. In Johnston, R.J. (Ed), The Challenge for Geography: A changing world, A Changing Discipline (pp 150-180). Oxford. Oxford Blackwell Publishers.

Kagoda A. M. (2016). Teaching of Geography in Uganda Secondary Schools: Reflections of Geography Teacher Trainees at the School Of Education, Makerere University, Uganda. Advances in Social Sciences Research Journal 3(5) 25-38.

(2008). The Effect of Land Tenure System on Womens' Knowledge-base and Resource Management in Manjiya County, Uganda. In Educational Research Review Vol.3(12),pp.365-369,December,2008. 
(1997) Geography Education in Uganda: A Critical Analysis of Geography Programs in National Teachers' Colleges. University of Alberta. PhD thesis.

Little .J. and Panelli, R (2003), Gender Research in Rural Geography. Gender, Place and Culture, Vol. 10, No 3, pp281-289.September 2003

Momsen. J.H, (1991)Women and Development in the Third World. London. Routledge.

Oberhauser. A. (2010) The Geography of Gender: A Global View. www.geo.wvu.edu/-oberhauser

Mlama, P., Marema, D., Makoy, H., Murage, L., Wagh, M. and Washika, K. (2005). Gender Responsive Pedagogy: A Teacher's Handbook: Nairobi: Forum for African Women Educationalists (FAWE).

Pinchenel,P. (1982). Environmental Analysis. In Graves,N.J. (Ed), UNESCO Source Book for Geography Education (pp1-14). Paris: Longman Prorok, C.V and Chhoker (eds.) Asian Women and their work. Indiana National Council For Geographic Education.

Reardon.B.(1993). Feminist Visions of Global Security. Albany: State University of New York Press. (1988). Educating For Global Responsibility. New York. Teachers' College Press.

The Ministry of Education and Sports. Uganda. (2008). Geography Teaching Syllabus. Senior 1-4. Kampala. National Curriculum Development Centre

Slater. J.(1977) The Poverty of Modern Geography Enquiry. In Peet. R (Ed.). Radical Geography: Alternative Viewpoints on contemporary Social Issues. Chicago: Maaroufa Press (pp. 40-58)

Smith .D.L.(1978). Values And The Teaching of Geography. Geographical Education 3

Toh, S.H(1987). Education for Participation. Third World Perspective. WCCI Forum 1(1), 20-43

Toh, S.H (1988) Flowing Water over Stones. Themes For Peaceful Pedagogies. In Occasional paper 88.1. Perspectives on Peace and Security, 33-47. Department of Educational Foundations, University of Alberta, Edmonton, Alberta

Toh.S.H and Cawagas. V.(1987). Peace Education; A Framework for Philippines. Quezon City. Phonix 